\title{
Assessment of Stormwater Drainage System for Small Urban Watershed: Case of Shambu Town, Oromia Region, Ethiopia
}

\author{
Habtamu Tamiru Dagne ${ }^{1} \quad$ Meseret Wagari Bortola $^{2}$ \\ 1.Department of Water Resources and Irrigation Engineering, Wollega University, Shambu Campus, \\ P.O.BOX 26 Ethiopia \\ 2.Department of Natural Resources Management, Wollega University, Shambu Campus, P.O.BOX 26 Ethiopia
}

\begin{abstract}
Stormwater runoff in a small urban watershed is one of the major challenging issues facing many countries where financial capacity is very weak to provide sufficient drainage systems. This study aims to assess the stormwater drainage system in the small urban watershed as a case study of Shambu town, Oromia Region, Ethiopia. The main objective of this study was to assess whether this excess stormwater runoff is due to hydrological change or insufficient hydraulic design of the existing drainage system in the town. The existing drainage system in this small urban watershed was analyzed by statistical analysis and the main purpose of this was to know whether the designed drainage systems were sufficient hydraulically. The existing drainage system in this small urban watershed was analyzed by statistical analysis and the main purpose of this was to know whether the designed drainage systems were sufficient hydraulically. The existing design document was taken in this analysis and field analysis also made to check whether the drainage was constructed according to the specification. The area also analyzed hydrologically by delineating the watershed using ArcSWAT and the peak discharge was computed the outlet of the watershed using Rational method. Some data such runoff coefficient and manning's values were also generated from the watershed based on the reality on the ground. The two results from hydrological and hydraulic models were compared and that of peak discharge obtained from rational method became greater than of the Peak discharge obtained from existing drainage measurement. Therefore, in this study it was concluded that since the watershed is steep in slope, it is contributing additional runoff to this small urban watershed, additional new $50 \%$ of the existing drainage system and rehabilitation works should be implemented to modify the draining capacity of the existing scheme. Additionally, managing and improper construction alignment problem in the existing system were identified, so to control this challenge periodic cleaning and modification of slope is recommended. Keywords: Hydraulic Model, Hydrological Model, Runoff, Small Urban Watershed, Stormwater
\end{abstract} DOI: $10.7176 /$ CER/12-9-01

Publication date:September $30^{\text {th }} 2020$

\section{Introduction}

Stormwater runoff is a challenging problem in a country where financial capacity is very limited. Urban storm water drainage facilities are part of the urban infrastructure elements and design of these facilities require due attention(Arisz \& Burrell, 2006). Drainage problems in urban areas introduce flooding, deterioration of roads, land degradation, sedimentation, water logging (Toryila et al., 2016). Urbanization increases impermeability of land by increasing the impervious surfaces that may include residential, commercial, paved roads, and parking lots which in turns contributes stormwater runoff(Adugna Belete, 2011).

It is dated back more than 50 years that the availability of both hydrologic data and computers was limited(Anonymous, 2001). The increase in urbanization in the last 50 years and development of impervious surfaces along with it changed the watershed and increase flood in the cities and this in turn made necessary the developments of new drainage models(Hu et al., 2020). Water has a key role when discussing the mechanical performance and lifetime of any traffic infrastructure(Mosaberpanah \& Khales, 2013). Increased water content reduces the bearing capacity of soil, which will increase the rate of deterioration and shorten the lifetime of the road and flooding. In such cases, the road will need rehabilitation more often than a well- drained road structures(Saara Aho, 2005).

In the design of highway/access road, highway storm water drainage structures are extremely important component. Provision of adequate drainage is an important factor in the location and geometric design of highways. Adequate level of service can be acquired by properly designing them. Initial cost, design life, and the risk of loss of use of the road way for a time due to runoff exceeding the capacity of the drainage structure, need to be considered in the design(AASHTO, 1990). The risk of urban floods due to climate change and growth in urbanization has enabled continued attention to the stormwater management field and controlling strategies. Many researchers and countries have successively proposed groundbreaking ideas for stormwater management and proposed different controlling measures(Wu et al., 2019).

Developing urban areas need appropriate drainage infrastructure to work efficiently in extreme events of rainfall and for rehabilitation works to keep the environmental safe(Dibaba, 2018). Infrastructure is one of the indispensable elements in the process of urbanization, wellness and continuity of urban growth. However, in 
developing countries like Ethiopia, numerous problems have made the supply of physical infrastructure and services to continually lag behind the urban population growth rate as cited (Dibaba, 2018). Practices and approaches to mitigate the negative environmental effects of stormwater runoff are numerous in number that include stormwater control measures (SCMs), sustainable urban drainage systems, water sensitive urban design, green infrastructure (GI), and low impact design (LID) some of the design should be implemented to control and minimize the effects of the stormwater runoff(Moore et al., 2018). For developing countries like Ethiopia where structural measures are difficult to be implemented due to financial limitation, non-structural measures such environmental protection and proper watershed management have a paramount role in combating stormwater runoff effects.

According to (Y \& Kemal, 2017) managing and improper construction alignment problem for the existing system causes the increment in stormwater runoff. In order to meet the above requirements and to assess the overall stormwater drainage performance of existing scheme and management within this study area, this research study was specifically designed setting the following objectives: to assess the performance of existing stormwater drainage system and the urban watershed by integrating hydrological model and hydraulic design, to generate the IDF curve of the town watershed and to identify the town urban watershed boundary that contributing excess stormwater for the watershed outlet.

\section{Methodsk}

\subsection{Description of the study area}

This study was conducted in Fincha sub basin of Abay River Basin, Ethiopia and this particular watershed was delineated setting the outlet at the town outlet. This delineated watershed is geographically found between $37^{0}$ $0.06^{\prime} 00^{\prime \prime} \mathrm{E}$ to $37^{0} 33^{\prime} 18^{\prime \prime} \mathrm{E}$ longitude and $09^{\circ} 21^{\prime} 11^{\prime \prime} \mathrm{N}$ to $10^{\circ} 01^{\prime} 00^{\prime \prime} \mathrm{N}$ latitude. The delineated watershed has a total area of $0.225 \mathrm{~km}^{2}$.

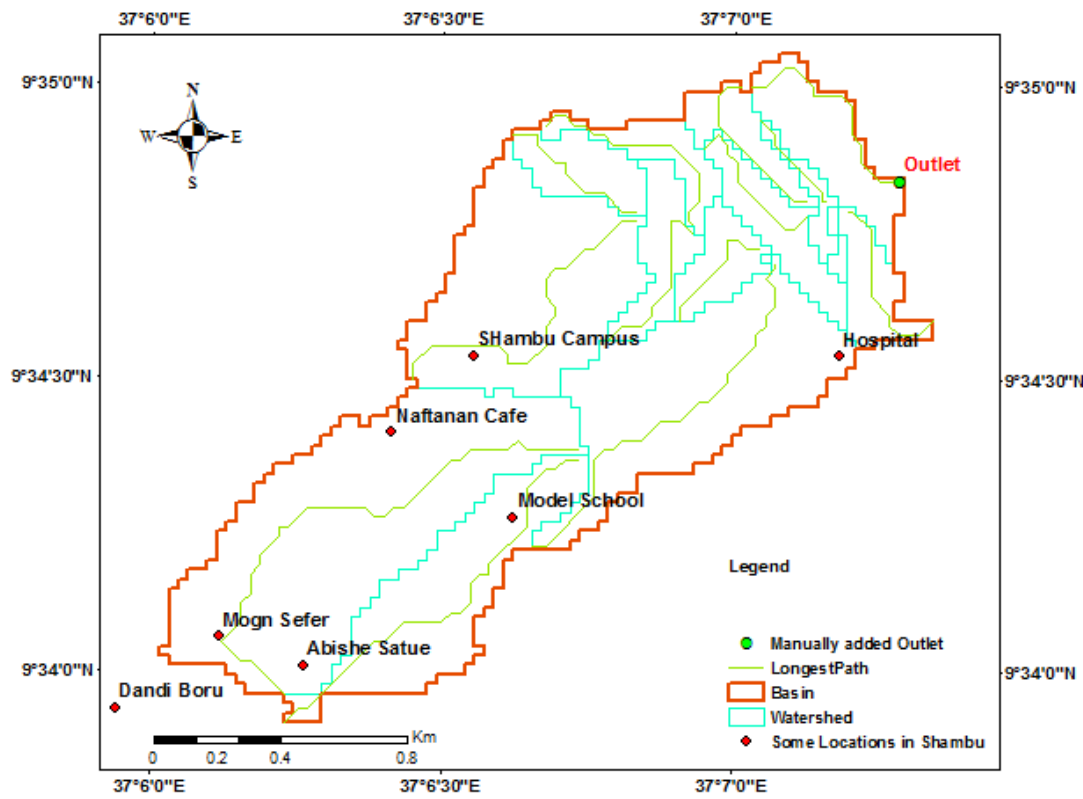

Figure 0-1: Map of the study area

\subsection{Topography}

Slope is the steepness or the change of elevation between two locations and it has a direct influence on Speeding up of stormwater runoff. High slope regions have high runoff and low infiltration rate that are not suitable for safety of drainage system, because of water cannot get enough time flow and be removed from the land or drainage. 


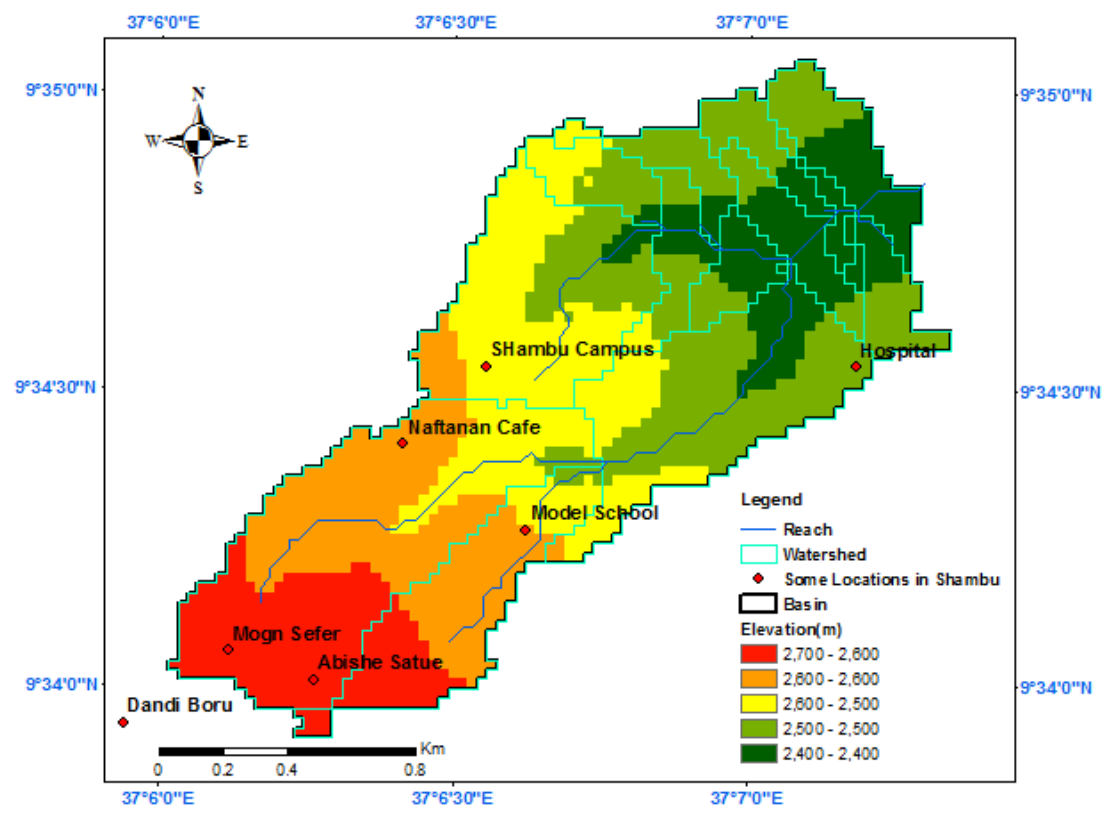

Figure 0-2: The topography map of the Watershed

\subsection{Soil type}

The soil type that was generated in ArcGIS for the delineated watershed is as follow and the detail of this soil types is put as legend on the right side of the map. The infiltration capacity of the soil type directly affects the probability of stormwater to occur.

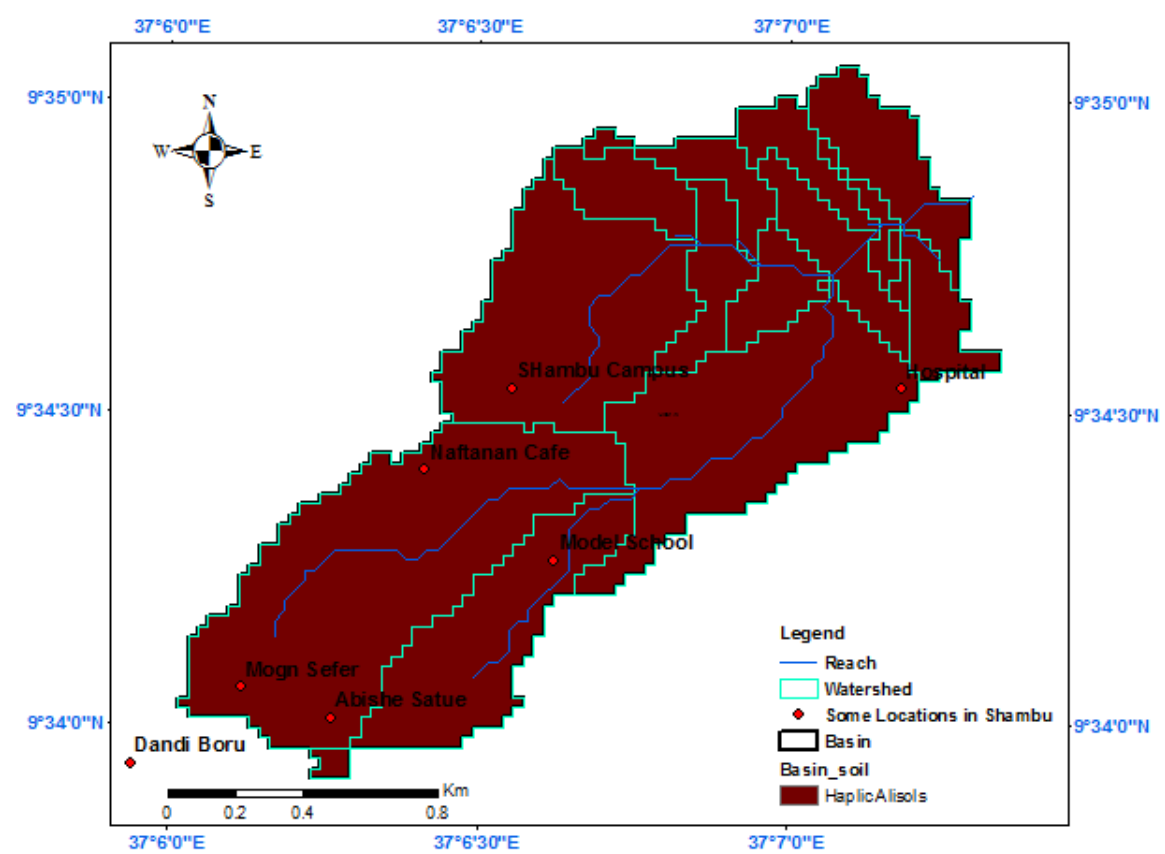

Figure 0-3: The soil type in Watershed

\subsection{Data to be used and processing}

To conduct this research, both primary and secondary data are collected through different techniques and from different governmental offices.

\subsubsection{Primary data}

1. interview

Interview was made with concerning bodies to know some ideas about the existing situation that the most likely reasons, effect of water drainage challenges and also the environmental challenges related to the improper utilization of the drainage systems in this watershed. 


\section{Physical Observations}

For this research, different images of different scenario related to drainage issues were directly taken from the site to reconnaissance the reality on the ground. Observations and discussion with residents were also made a measuring the size of the existing drainage structures, measuring the elevation difference.

\subsubsection{Secondary data}

This was important to generate information to look at the causes of poor drainage challenges and unconstructed stormwater drainage. Both quantitative and qualitative techniques in data collection and analysis were utilized as main instruments.

\subsection{Hydrological model and Hydraulic design}

\subsubsection{Hydrological model}

The main purpose of this hydrological modeling stormwater runoff is to determine the peak or maximum discharge which be contributed by the watershed.

\subsubsection{Rational Method}

This method is one of the most commonly used easy models for peak discharge computation method in stormwater runoff design, and this is primarily based on the concept that the peak discharge from a watershed will always happen when the rain takes long enough at its maximum intensity to enable all portions of the basin to contribute to the flow. This method is applicable for the watershed area of less than 200hectare.

Where $Q=$ Peak discharge $(\mathrm{m} 3 / \mathrm{s})$

$$
\boldsymbol{Q}=\mathbf{0 . 2 7 8} * \boldsymbol{C} * \boldsymbol{i} * \boldsymbol{A}\left(\frac{\mathrm{m}^{3}}{\mathrm{~s}}\right)
$$

\section{Equation 0-1}

$$
\begin{aligned}
& C=\text { runoff coefficient (dimensionless) } \\
& i=\text { rainfall intensity }(\mathrm{mm} / \mathrm{Hr} .) \\
& A=\text { watershed total area }\left(\mathrm{km}^{2}\right)
\end{aligned}
$$

In this rational method, to calculate the runoff coefficient $\mathrm{C}$ if different land use land cover of different infiltration will occur we can take the weighted runoff coefficient $(\mathrm{Cw})$ instead of using single $\mathrm{C}$. Therefore, the above rational method formula will take $\mathrm{Cw}$ as follows.

$$
\begin{aligned}
& Q=0.278 * C W * i * A\left(\frac{m^{3}}{s}\right) \\
& C w=\frac{A 1 * C 1+A 2 * C 2+\cdots A i * C *}{A 1+A 2+\cdots A i}
\end{aligned}
$$

Equation 0-2

Equation 0-3

Where, $\mathrm{Cw}=$ is the weighted runoff coefficient.

\subsection{Hydraulic Design}

When a storm drain is not flowing full, it operates as an open channel and the hydraulic properties can be calculated using open channel techniques. The flow in a conduit operating as an open channel can be evaluated numerically using the Uniform Flow Equation. Concrete-lined channels are rectangular or trapezoidal channels in which reinforced concrete is used for lining the channel banks and/or bottom. Concrete-lined channels may be permitted only where existing right-of-way restrictions preclude the use of other channel types. Discharge is determined for known geometries of the drainage using one of discharge computation. Manning's equation is one of the commonly used formula for uniform flow in an open channel, but the Manning's roughness coefficient needs to be considered variable, dependent upon the depth of flow in that open channel and this Manning's equation. This equation also used for calculating the cross-sectional area (A), wetted perimeter (P), and hydraulic radius (R) for flow of a specified depth in an open channel and pipe flow.

$$
Q=\frac{A R^{\frac{3}{2} * S^{\frac{1}{2}}}}{n}
$$

\section{Equation 0-4}

Where, $\mathrm{Q}=$ Peak or design discharge in the channel $(\mathrm{m} 3 / \mathrm{s})$

$$
\begin{aligned}
& A=i \text { is the wetted cross-sectional area }(\mathrm{m} 2) \\
& R=i \text { s the hydraulic radius }(\mathrm{m}) \\
& n=\text { is the roughness or manning's coefficient (dimensionless) and } \\
& S=i \text { is the bed slop of the channel }(\mathrm{m} / \mathrm{m})
\end{aligned}
$$

\subsection{Intensity-Duration-Frequency Curves (IDF)}

An intensity-duration-frequency curve (IDF curve) is a mathematical function that relates the rainfall intensity with its duration and frequency of occurrence. These curves are commonly used in hydrology for flood forecasting and civil engineering for urban drainage design. However, the IDF curves are also analyzed in hydrometeorology because of the interest in the time concentration or time-structure of the rainfall(de Paola et al., 2014). For this study, Intensity duration frequency (IDF) was developed from storm events of 21years from 1987-2007 for different durations of $5 \mathrm{~min}, 15 \mathrm{~min}, 30 \mathrm{~min}, 45 \mathrm{~min}, 1 \mathrm{hr}, 2 \mathrm{hrs}, 3 \mathrm{hrs}, 12 \mathrm{hrs}$ and $24 \mathrm{hrs}$. The return period of the maximum annual rainfall frequency also developed. 


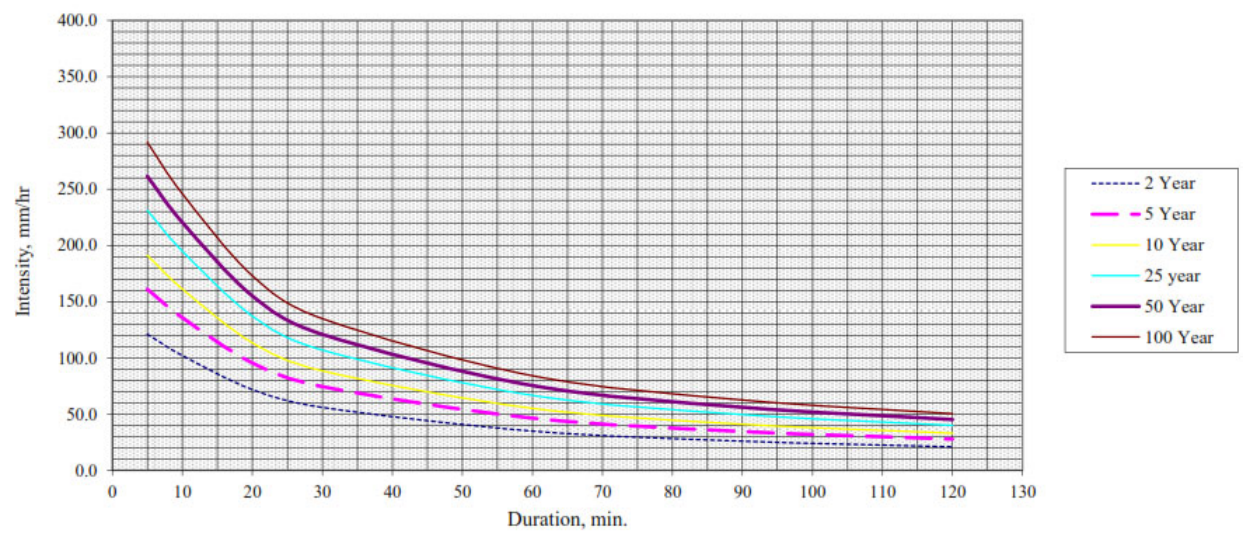

Figure 0-4: Intensity Duration frequency (IDF) curves of the study area

From the intensity duration frequency (IDF) curves, the following table summarized.

Table 0-1: Intensity duration frequency (IDF) curves of the study area

\begin{tabular}{|l|l|l|l|l|l|l|l|l|}
\hline Duration/Return period & 2 & 5 & 10 & 15 & 20 & 25 & 50 & 100 \\
\hline $5 \mathrm{~min}$ & 24.93 & 18.12 & 14.72 & 12.48 & 7.36 & 5.19 & 1.36 & 0.80 \\
\hline $30 \mathrm{~min}$ & 25.19 & 18.31 & 13.45 & 11.40 & 6.72 & 4.74 & 1.24 & 0.73 \\
\hline $45 \mathrm{~min}$ & 21.20 & 15.41 & 9.93 & 8.42 & 4.96 & 3.50 & 0.92 & 0.54 \\
\hline $1 \mathrm{Hr}$ & 23.37 & 16.98 & 9.74 & 8.26 & 4.87 & 3.43 & 0.90 & 0.53 \\
\hline $2 \mathrm{Hr}$ & 22.06 & 16.03 & 8.95 & 7.59 & 4.48 & 3.16 & 0.83 & 0.49 \\
\hline $3 \mathrm{Hr}$ & 23.71 & 17.23 & 8.85 & 7.51 & 4.42 & 3.12 & 0.82 & 0.48 \\
\hline $12 \mathrm{Hr}$ & 25.54 & 18.56 & 8.85 & 7.50 & 4.42 & 3.12 & 0.82 & 0.48 \\
\hline $24 \mathrm{hr}$ & 31.45 & 22.86 & 8.77 & 7.44 & 4.38 & 3.09 & 0.81 & 0.48 \\
\hline
\end{tabular}

\subsection{Research Methods flowchart}

The general flowchart that shows the detailed procedures or steps is conceptualized as indicated in figure 2-4. In this study, both primary and secondary data were used in assessing the existing stormwater runoff drainage system by integrating the hydrological model and hydraulic design.

At first instance, the hydrological model was done and the peak discharge determined using the rational method, and secondly, the hydraulic design was done using manning's equation to determine the stormwater drainage capacity. The result obtained from the hydrological model compared with that of hydraulic design and final judgment was made. Judgment was made from different perspectives like improper management and alignment design of the existing stormwater runoff drainage system.

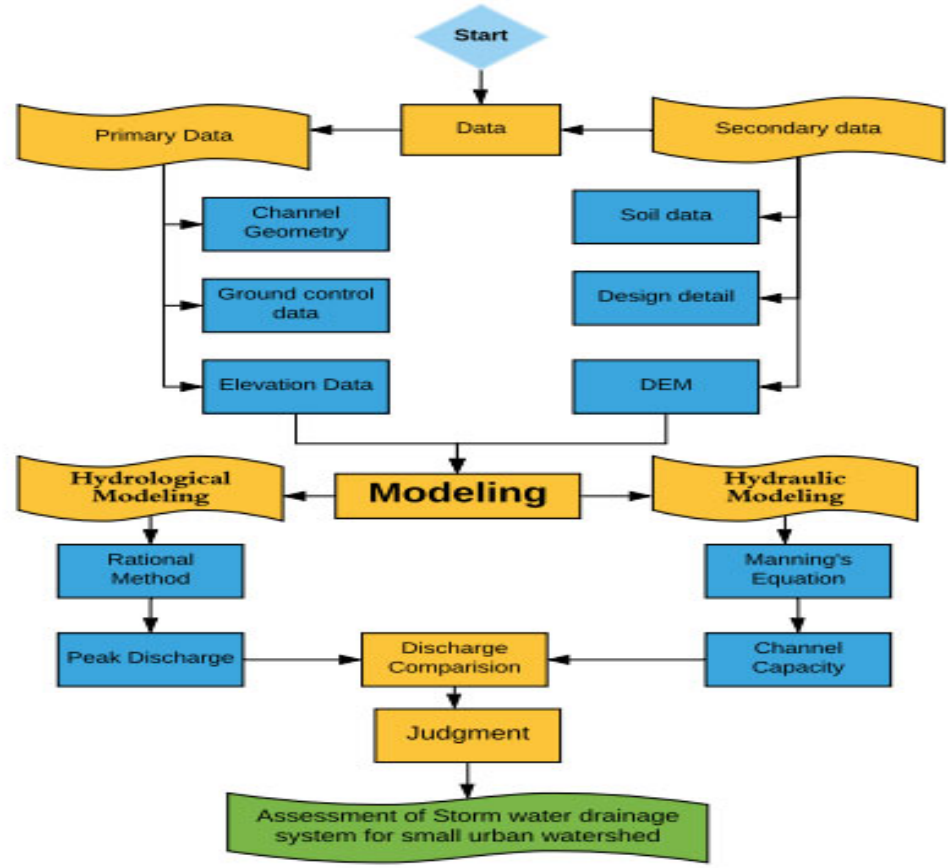

Figure 0-5: The general Flowchart of the method 


\section{Result and Discussion}

\subsection{Result}

The existing stormwater runoff drainage services are open drainage lines. Open drainage channels, constructed by masonry are found along the watershed and side or walkway roads. In many places in the area, walkway or access roads serve as wide-open channels with severe erosion and flooding problems. These rectangular open channel stormwater runoff drainage lines are traveling or transporting high flood which comes from slightly steep areas and because of the speed of this flood, the probability to infiltrate is very small and almost all raining water will be changed into runoff and in turn, will become beyond the capacity of the channel. The hydrological model result was compared with that of hydraulic design result.

\subsection{Hydrological model result}

From the general equation of rational method, the weighted runoff coefficient $\mathrm{Cw}$, the rainfall intensity(i) and the total watershed area were calculated based on the reality on the ground for this specific study. The weighted runoff coefficient $\mathrm{Cw}$, for different land uses in the watershed were generated and summarized in the following table.

Table 0-1: Weighted runoff coefficient for different land uses

\begin{tabular}{|l|l|l|l|}
\hline S/N & \multicolumn{1}{|c|}{ Land use } & Runoff coefficient. $\mathbf{C w}$ & \multicolumn{1}{|c|}{$\begin{array}{c}\text { Covered area } \\
\mathbf{K m}^{2}\end{array}$} \\
\hline 1 & Dominantly cultivated & 0.35 & 0.109 \\
\hline 2 & Moderately cultivated & 0.43 & 0.112 \\
\hline 3 & Urban & 0.38 & 0.044 \\
\hline
\end{tabular}

The weighted runoff coefficient $\mathrm{Cw}$ :

$$
\begin{aligned}
& \boldsymbol{C} \boldsymbol{w}=\frac{\mathbf{0 . 1 0 9 * 0 . 3 5 + 0 . 1 1 2 * 0 . 4 3 + 0 . 0 4 4 * 0 . 3 8}}{\mathbf{0 . 1 0 9 + 0 . 1 1 2 + 0 . 0 4 4}} \\
& C w=\frac{0.038+0.048+0.017}{0.224} \\
& C w=0.46
\end{aligned}
$$

For the three different land uses and different area coverage, the total or weighted runoff coefficient that can represents the reality on the ground is $\mathrm{Cw}=0.46$.

\subsection{Intensity-Duration-Frequency Curves (IDF)}

From the Log-Pearson type III fit curve, it was revealed that the $\mathrm{R}^{2}$ value for different design and return period good. Since of the flood hazards happened per 2 years in once we need to check the peak flood or discharge for longest return period.

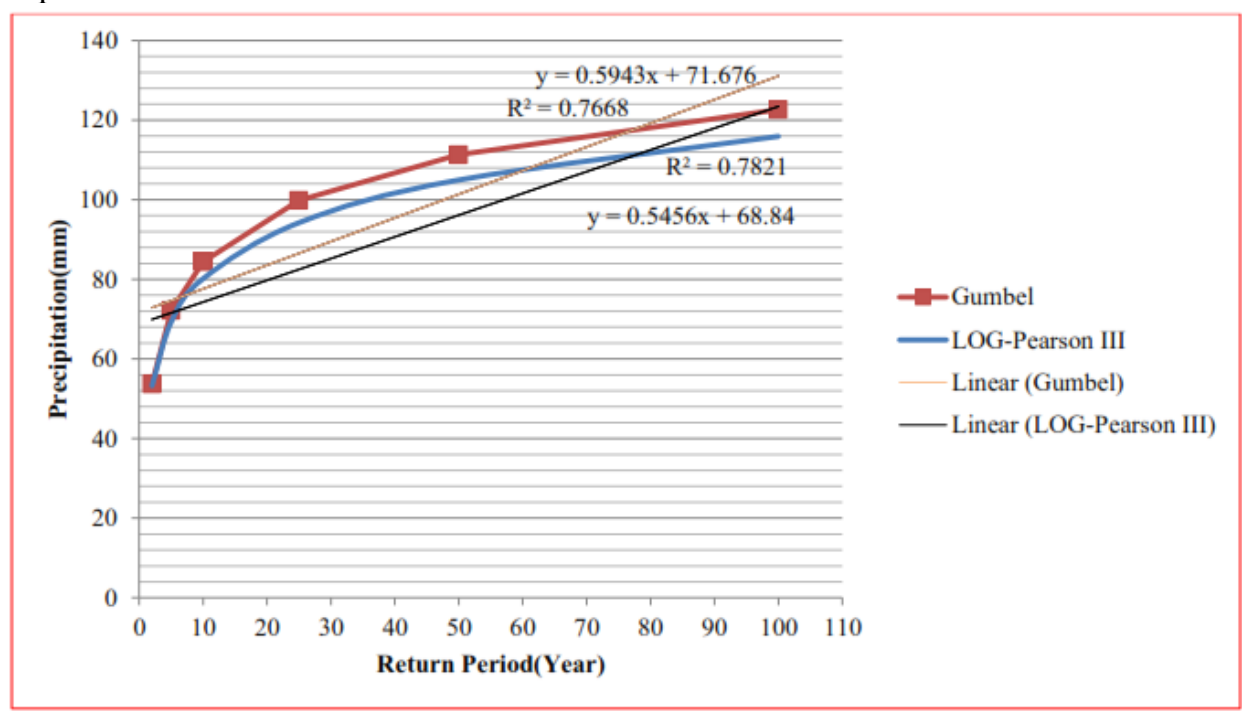

Figure 0-1: The fit curve by Log-Pearson type III

Generally, the peak discharge which will happen once in 2 years return period was selected in this specific study, since the maximum or extreme event with $31.45 \mathrm{~mm} / \mathrm{Hr}$.

$$
\begin{aligned}
& Q=0.278 * 0.45 * 31.45 * 0.224\left(\frac{m^{3}}{s}\right) \\
& Q=1.96\left(\frac{m^{3}}{s}\right)
\end{aligned}
$$




\subsection{Hydraulic design result}

The manning's equation is considered in this existing drainage system analysis.

$$
Q=\frac{A R^{\frac{3}{2}} * S^{\frac{1}{2}}}{n}
$$

Detail of the existing drainage specification:

- Bottom width, $\mathrm{b}=1.5 \mathrm{~m}$

- $\mathrm{y}=1.45 \mathrm{~m}$

- $\quad$ slope $=0.04$

- side slope $1 \mathrm{H}: 1 \mathrm{~V}$

- Manning's coefficient $\mathrm{n}=0.012$

- Channel shape: Rectangular

$$
\begin{aligned}
& A=b * y=1.45 m * 1.5 m=2.175 \mathrm{~m} 2 \\
& P=2 y+b=2 * 1.45+1.5=4.4 m
\end{aligned}
$$

Hydraulic Radius (R):

$\mathrm{R}=\mathrm{A} / \mathrm{P}=2.175 / 4.4=0.49$

Peak Discharge:

$$
\begin{aligned}
& Q=\frac{A R^{\frac{3}{2}} * S^{\frac{1}{2}}}{n} \\
& \mathrm{Q}=\left(2.175^{*}(0.49) \wedge(3 / 2)^{*} \square(0.004) \rrbracket \wedge(1 / 2)\right) / 0.04 \\
& \mathbf{Q}=\mathbf{1 . 1 8 \mathbf { m } ^ { 3 } / \mathbf { s }}
\end{aligned}
$$

\subsection{Conclusion}

According to the result of this study, the existing stormwater runoff drainage services are inadequate to carry the peak or maximum discharge for the return period by which this peak discharge will happen. Due to the ignorance of hydrological model or watershed model during the design of the drainage system, it failed to convey the excessive stormwater with considering hydraulic design only. At first instance, the existing drainage system was conveying all entering stormwater, but after few years it became fail to convey because additional excessive stormwater is entering into the drainage system which is contributed by the watershed. The other issues assessed or identified in this study was, the mismanagement and improper drainage alignment that revealed the overland flow storing outside the drainage system and some of excess stormwater is not getting the drainage system. Additionally, even the existing drainage system were totally clocked by dirty materials and due to this reason the stormwater runoff is not the getting channel rather it simply flowing over the land and on roads. And also due to the topography or nature this Shambu town location, the speed of the runoff if very high and there is no the probability to infiltrate to the soil. Finally, this study concluded that the assessment of the stormwater runoff drainage system needs proper management of the watershed, and giving awareness for the community on the existing drainage system is the state-of-art of the modern way of keeping the urban area safely.

\section{References}

AASHTO. (1990). A Policy on Geometric Design of Highways and Streets 19901. AASHTO (1990) A Policy on Geometric Design of Highways and Streets 1990, 7th Editio. www.transportation.org

Adugna Belete, D. (2011). Road and urban storm water drainage network integration in Addis Ababa: Addis Ketema Sub-city. Journal of Engineering and Technology Research, 3(7), 217-225. http://www.academicjournals.org/JETR

Anonymous. (2001). Water Resources Research Grants. Eos, Transactions American Geophysical Union, 66(3), 17. https://doi.org/10.1029/eo066i003p00017-03

Arisz, H., \& Burrell, B. C. (2006). Urban drainage infrastructure planning and design considering climate change. 2006 IEEE EIC Climate Change Technology Conference, EICCCC 2006, June 2006. https://doi.org/10.1109/EICCCC.2006.277251

de Paola, F., Giugni, M., Topa, M. E., \& Bucchignani, E. (2014). Intensity-Duration-Frequency (IDF) rainfall curves, for data series and climate projection in African cities. SpringerPlus, 3(1), 1-18. https://doi.org/10.1186/2193-1801-3-133

Dibaba, W. T. (2018). a Review of Sustainability of Urban Drainage System: Traits and Consequences / Revisão Da Sustentabilidade De Um Sistema De Drenagem Urbana: Características E Conseqüências. Journal of Sedimentary Environments, 3(3), 131-137. https://doi.org/10.12957/jse.2018.37825

Hu, S., Fan, Y., \& Zhang, T. (2020). Assessing the effect of land use change on surface runoff in a rapidly Urbanized City: A case study of the central area of Beijing. Land, 9(1). https://doi.org/10.3390/land9010017

Moore, T. L., Rodak, C. M., Ahmed, F., \& Vogel, J. R. (2018). Urban Stormwater Characterization, Control and Treatment. Water Environment https://doi.org/10.2175/106143018x15289915807452 
Mosaberpanah, M. A., \& Khales, S. D. (2013). The role of transportation in sustainable development. ICSDEC 2012: Developing the Frontier of Sustainable Design, Engineering, and Construction - Proceedings of the 2012 International Conference on Sustainable Design and Construction, September, 441-448. https://doi.org/10.1061/9780784412688.053

Saara Aho, T. S. (2005). Managing Drainage on Low Volume Roads. 37. http://www.roadex.org/uploads/publications/docs-RII-S-EN/Drainage_English.pdf

Toryila, M., Scholar, M. T., \& Point, C. (2016). the Effects of Poor Drainage System on Road Pavement : a Review the Effects of Poor Drainage System on Road Pavement : a Review. August, 218-225.

Wu, J., Wu, X., \& Zhang, J. (2019). Development trend and frontier of stormwater management (1980-2019): A bibliometric overview based on CiteSpace. Water (Switzerland), 11(9). https://doi.org/10.3390/w11091908

Y, B., \& Kemal, A. (2017). The Impacts of Climate Change on Rainfall and Flood Frequency: The Case of Hare Watershed, Southern Rift Valley of Ethiopia. Journal of Earth Science \& Climatic Change, 08(01), 1-5. https://doi.org/10.4172/2157-7617.1000383 